\title{
Selection and justification of the design of polymer sieves of air-sieve machines
}

\author{
Aleksandr Grishkov ${ }^{1}$, Evgeneiy Chebotarev ${ }^{1}$, and Andrey Boiko ${ }^{2, *}$ \\ ${ }^{1}$ Federal Scientific Agroengineering Center VIM, 1-st Institutsky proezd, 5, Moscow, 109428, Russia \\ ${ }^{2}$ Don State Technical University, Gagarin Square, 1, Rostov-on-Don, 344000, Russia
}

\begin{abstract}
Post-harvest process of the grain is characterized by a large percentage of impacts on grain material by using cleaning machines and transporting devices. The grain material has a large number of macro and micro seeds damage at the exit, which negatively affects to the quality indicators and seeds sowing properties. This problem is undoubtedly actual, and one of the ways to solve is using of new types of construction from polymer.
\end{abstract}

\section{Introduction}

Improvement of post-harvest technological processes seeds and equipment of their mechanization in selection and seed production, as well as during the cleaning of food grains is impossible without using of new types of materials. The target of using new materials in the machines construction for grain post-harvest processing is to improve the quality of seeds in its separation. Issues of increasing the yield qualities of seed material at this stage are significant and priority. The productive qualities of seeds (according to L.K. Sechnyakov, 1981) are understood to be the totality of their intrinsic properties, which in a certain way can influence the formation of crops as a photosynthetic system - its structure, growth and development, which ultimately determines the biological and economic yield.

Post-harvest processing of seeds includes technological operations such as cleaning, loading, unloading and transporting grain material. In addition, each operation affects to the seed quality. Special requirements are imposed on injuring the seeds of cleaned crops (Figure 1, 2).

\footnotetext{
${ }^{*}$ Corresponding author: andreyboi@yandex.ru
} 


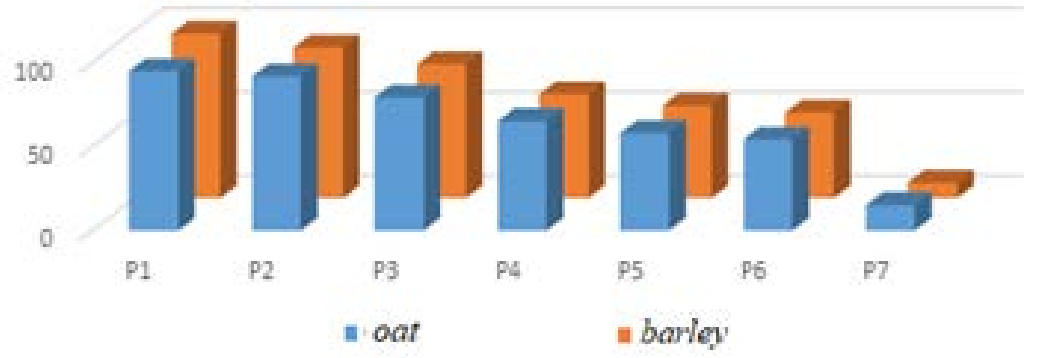

Fig. 1. Effect of internal damage to seeds on field germination: P1- seeds (control); P2, P3 - seeds with dents in the area of the endosperm and the embryo; P4, P5 - seeds with up to four internal cracks and more; P6 - seeds with chips (potholes) in the endosperm; P7 - seeds with damaged embryos.

Studies have shown that most of the seeds during post-harvest processing are injured by the working bodies of the grain cleaning machines. The total micro injuries of seeds during their post-harvest treatment in some cases reaches $40-50 \%$. [1,2,4].

We hypothesize that changing the type of material of the surface of contact with the grain of the working body, directly carrying out the process an it can reduce the impact on the grain material. It will help reduce macro and micro injury to seeds. The use of polymerbased sieves made from ultrahigh-molecular polyethylene in air-sieve machine constructions may be an alternative to steel metal sieves (Figure 2).
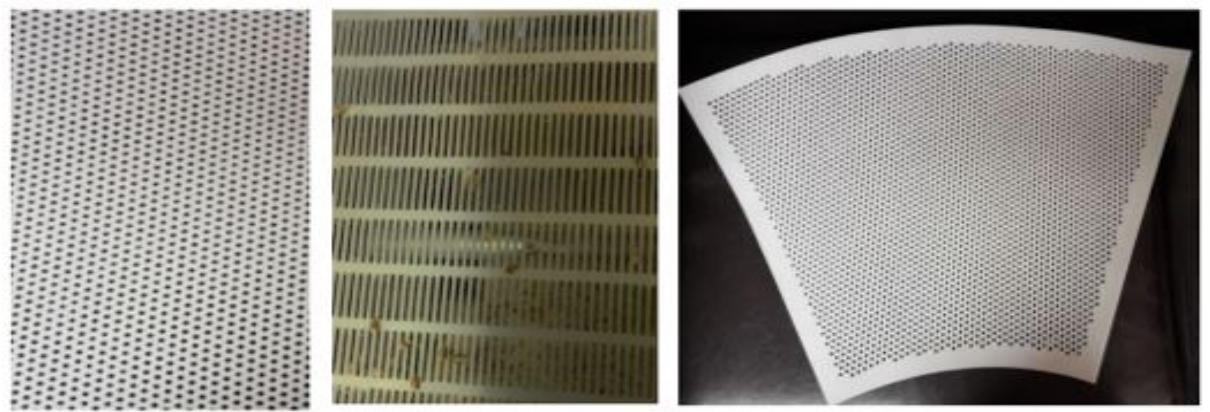

Fig. 2. Sieve made from ultra high molecular weight polymer for laboratory studies

During the separation of grain on this type of sieves, new processes of layer stratification and changes in the probability of seeds passing into the sieve holes are observed due to changes in the friction coefficient of the surface of polymer sieves and grains, an increase in the speed of sieve passage through technological parameters $[1,2,3]$. There remain unresolved questions of the choice and justification of the construction of these types of sieves for various airborne sieve machines.

\section{Materials and methods}

We presented following data (Table 1) making analogies polymer sieves with metal sieves and taking into account the correlation coefficient, referring to the works of I. G. Vorontsova, Kozhukhovsky I. E., Kopyshev P. P., Povlovsky G. G., Gladkov N. G. 
Table 1. Specific load on polymer sieves during cleaning various crops

\begin{tabular}{|c|c|c|}
\hline Crop & $\begin{array}{c}\text { Preliminary cleaning process , } \\
\mathrm{m}^{2} \mathrm{~kg} / \mathrm{s}\end{array}$ & Main cleaning process, $\mathrm{m}^{2} \mathrm{~kg} / \mathrm{s}$ \\
\hline Wheat & 17 & 6 \\
\hline Rye & 14 & 4 \\
\hline Barley & 14 & 4 \\
\hline Oats & 11 & 3 \\
\hline Buckwheat & 8 & 3 \\
\hline Rice & 11 & 3 \\
\hline
\end{tabular}

The data given in Table 1 does not take into account the following parameters: the presence of large and small impurities in the initial material, fractional, humidity. The obtained data can be used only for approximate calculations. The evaluation of sieving on polymer sieve grain (P) can be determined by the formula obtained in Federal Scientific Agro engineering Center VIM:

$$
\mathrm{P}=\frac{\mathrm{L}_{1}}{\frac{\mathrm{L}_{1}}{\mathrm{CQ}}+\frac{\mathrm{b}}{\mathrm{c}}}
$$

where: $\mathrm{Q}$ is amount of clean original heap entering to the sieve; $\mathrm{L}_{1}-$ is the length of the sieve; $\mathrm{c}, \mathrm{b}$ - experimental coefficients.

The regularity of the separation process, expressed by dependence (2), makes it possible to approximately determine the parameters required for the design of modernized sieve mills using polymer sieves (Figure 3).

$$
\varepsilon=\frac{1}{1+\frac{\mathrm{cbq}}{\mathrm{t}}}
$$

where: P is sieving grain in time; $\mathrm{c}$ is coefficient of amount small fraction; Q is feed on the sieve.

\section{tons/m hour}

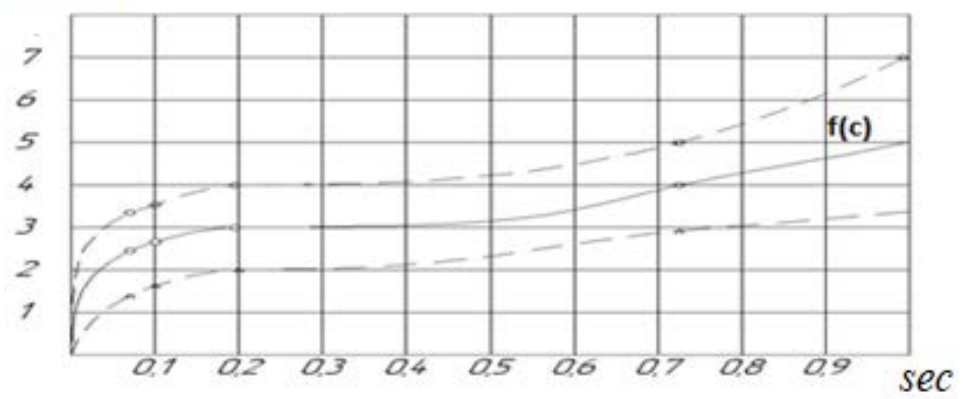

Fig. 3. Relationship between the separation factor $\mathrm{c}$ and the optimum feed rate $\mathrm{Q}$ for polymer sieves with oblong holes.

The processed material is wheat. Given the value of the separation coefficient $\mathcal{E}$, you can determine the required length of the polymer sieve:

$$
1=\frac{\mathrm{cbq}}{\frac{1}{\varepsilon}-1}
$$

Experimental confirmation of this technique was carried out by entering the laboratory tests on an experimental setup (Figure 4). When conducting an experimental study, experimental planning methods were used. 

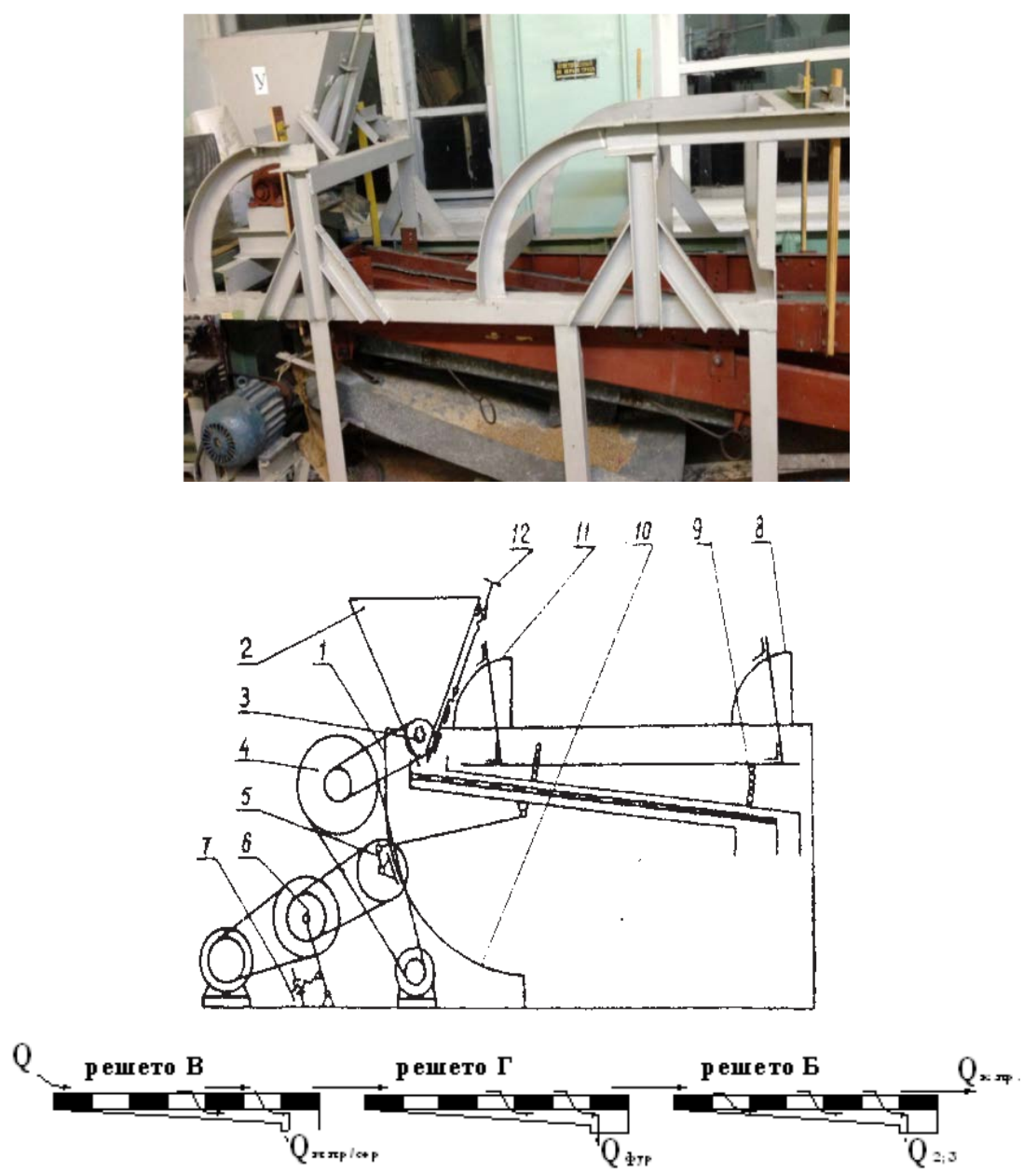

(a)

Fig. 4. Bench installation for determining grain separation processes on polymer sieves in a threelattice single-tier mill and the scheme of a real sieve module.

\section{Results and discussions}

The study of the separation of wheat on polymer sieves shows that the relationship between the permissible unit loads, the working dimensions of the holes and the average sizes of the signs of seed divisibility can be expressed by an approximate empirical formula

$$
\mathrm{q}_{\mathrm{F}}=\mathrm{k}_{1} \mathrm{c}_{\mathrm{k}}-\mathrm{k}_{2} \text {, }
$$

where: $c_{k}=\frac{a}{M}-$ the ratio of the average working size of the sieve holes a to the average size of the signs of divisibility of the seeds being processed $M ; k_{1}$ и $k_{2}$ are experimental coefficients.

For polymer sieves with round holes:

$$
\mathrm{q}_{\mathrm{F}}=317 \mathrm{c}_{\mathrm{k}}-400 ;
$$


For polymer sieves with oblong holes:

$$
\mathrm{q}_{\mathrm{F}}=528 \mathrm{c}_{\mathrm{k}}-600 \text {. }
$$

The completeness of the selection of various components of the specific performance of polymer sieves is expressed by the dependence (8).

$$
\lg \varepsilon=-10-3 \mathrm{qF}(3,45+0,0745 \beta)
$$

\section{Conclusion}

The analysis of the separation process shows that the screening capacity of polymer sieves with oblong holes is higher than that with round ones, but the latter emit straw impurities more efficiently. Based on the dependences, an algorithm for calculating the parameters of polymer sieves is obtained.

\section{References}

1. Moskovskiy M.N. Synthesis of system solutions of the technological process of obtaining seeds on the basis of structural and functional modeling: diss. doc tech. Sciences: 05.20.01 / Krasnodar, 2017, 491p.

2. Pekhalsky I.A., Moskovskiy M.N. Decrease in traumatizing seeds by sieves // Rural mechanization. 2015. No. 9. P. 22-23.

3. Moskovskiy M.N., Boyko A.A. Justification of various schemes for cleaning a graincleaning unit, when obtaining seed material in diversified agricultural production // Dona Engineering Bulletin [Electronic resource]: electron. nauch.- innovts. journals - 2014. - No 2. - Mode of access: http://www.ivdon.ru/ru/magazine/archive/n2y2013/1625 - Title. from the screen. - No state. registration number 0421100096.

4. Dorochov, A., Moskovskiy, M., Chaava, M. Transporting devices for grain with new types of working units from polymeric materials / International Conference on Modern Trends in Manufacturing Technologies and Equipment (ICMTMTE 2018) electronic edition. MATEC Web of Conferences. 2018. p. 02076. 